\title{
The Effect of Physical Play Experiences on Early Childhood Non-Cognitive Skills Development
}

\author{
Yuko Suzuki ${ }^{1}$ \\ ${ }^{1}$ Department of Early Childhood Education, Aichi University of Education, Japan \\ Correspondence: Yuko Suzuki, Department of Early Childhood Education, Aichi University of Education, Japan. \\ Tel: 81-566-262-258.
}

Received: September 24, 2020

Accepted: October 28, 2020

Online Published: November 17, 2020

doi:10.20849/jed.v4i3.827

URL: https://doi.org/10.20849/jed.v4i3.827

\begin{abstract}
This study aimed to verify the hypothesis that the acquisition of non-cognitive skills is affected by physical play experiences in early childhood. Research reports from the Organization for Economic Co-operation and Development state that the development of non-cognitive skills is affected by factors such as the quality of care and play experiences in early childhood. However, there is insufficient evidence regarding this hypothesis. To provide concrete evidence on how non-cognitive skills develop, this cross-sectional retrospective study was conducted. First, a questionnaire survey was conducted with university students and structural equation modeling was used to study the effect physical play experiences in early childhood had on non-cognitive skills in university, as represented by the Big Five personality traits. Second, to examine the perceived benefits of physical play experiences, participants were asked to write freely about their autobiographical memories of physical play experiences in early childhood. The narratives were visualized through co-occurring network analyses with text mining using KH Coder. The results showed a correlation between sufficiently rich physical play experiences in early childhood and the adult personality trait of attachment. Additionally, a correlation between personality traits and the quantity and quality of the subjective benefits of physical play experiences was observed. These findings imply the importance of physical play experiences during early childhood as the determinants of the development of non-cognitive skills.
\end{abstract}

Keywords: non-cognitive skills, physical play in early childhood, structural equation modeling, co-occurrence network analysis in text mining

\section{Introduction}

Recently, the development and support of non-cognitive skills have become core issues in early childhood education and are being incorporated into early childhood education curricula worldwide (Cherrington, \& McLaughlin, 2018; Cherrington, 2018; Organisation for Economic Co-operation and Development, 2018). Research affirms the importance of supporting the development of non-cognitive skills in children for positive short- and long-term outcomes (Shonkoff \& Phillips, 2000). Additionally, non-cognitive skills are effectively developed in early childhood when brain plasticity is high (Cunha \& Heckman, 2007), and research into the development of non-cognitive skills continues to advance globally. However, reports on the acquisition and development of non-cognitive skills in early childhood are limited to the impact of the quality of childcare and play experiences on these skills (Rosenthall \& Gatt, 2010). The limited research in this area may be partially owing to the emphasis on improving the quality of play rather than the acquisition or development of non-cognitive skills in early childhood (Muto, 2016).

Conversely, issues related to physicality have garnered much attention in recent years, including the decline in the level of and willingness to engage in physical activity among children. Researchers have expressed concerns that such changes in physicality are related to the noted changes in the quality of play (Nakamura, 2004; Sawae, Kizuka \& Nakagomi, 2014). As such, attention has been directed to developing the mind and sociability of children-referred to as "non-cognitive skills"-in addition to developing their physical health through the promotion of physical play activities that move the body. Professionals in early childhood education advocate for the importance of non-cognitive skills and have devised effective means of providing appropriate instruction to young children with intention (McLaughlin, Aspden, \& Clarke, 2017; Rosenthal \& Gatt, 2010). However, there are few specific findings regarding the relationship between and influence of physical health and physical play 
activities relative to non-cognitive skills. By revealing the relationship between physical play activities in early childhood and non-cognitive skills, it may be possible to offer suggestions on how non-cognitive skills develop the significance of physical play activities, and the development of interventions for impacting the development of non-cognitive skills.

This study was based on the assumption that demonstrating how physical play experiences in early childhood impact the development of non-cognitive skills could provide an important perspective for the enhancement of early childhood education. Specifically, this study aimed to clarify the determinants and mechanisms involved in the development of children's non-cognitive skills.

\section{Background}

This section outlines previous studies on the relationship between physical play experiences in early childhood and non-cognitive skills that inform this study.

\subsection{The Definition of Non-cognitive Skills in This Study and the Big Five as an Applied Concept}

The achievements from Heckman's (2013) Perry Preschool Project resulted in a focus on non-cognitive skills (i.e., the counterpart of cognitive skills) as an educational effect during early childhood (Taguchi, 2017). Heckman found that cognitive skills in early childhood and childhood cannot alone explain individual differences in adult wages. Therefore, Heckman conceptualized social and emotional characteristics and personality as associated with social success. Additionally, Heckman reported that the development of both cognitive skills and non-cognitive skills, including self-control, self-esteem, conscientiousness, and self-discipline, promote lifelong success (Kautz, Heckman, Diris, Weel, \& Borghans, 2014). Furthermore, the Organisation for Economic Co-operation and Development (OECD, 2015) defines social and emotional skills as measurable non-cognitive skills that are manifested in consistent thought, emotion, and behavior patterns; can be developed through school education or informal learning; and have an important impact on social and economic performance throughout the lifespan.

Many longitudinal cohort studies have examined the impact of non-cognitive skills on the social life of an individual. Such studies have been conducted not only in the United States but also in other countries including Australia (Marks, 2016), New Zealand (Silva, 1990), the United Kingdom (Goodman, Joshi, Nasim, \& Tyler, 2015), and Norway (Magnus et al., 2006). However, Bolli and Hof (2014) noted that, although many studies suggested that non-cognitive skills substantially affect life outcomes, little is currently known about the impact of education on non-cognitive skills; thus, the authors focused on work-based education in Switzerland and asserted that such education has a greater impact on non-cognitive skills than school-based higher education. Carneiro, Crawford, and Goodman (2007) similarly analyzed the determinants of cognitive and non-cognitive skills among 11-year-olds in the UK; they found that both skills are strongly dependent on the family background and home learning environment of children, and that non-cognitive skills may be more affected by such factors.

However, the definitions of non-cognitive skills are diverse (Carneiro et al., 2007), and researchers question what "none" refers to in "non-cognitive skills." The term was originally coined in the field of economics. Given that non-cognitive skills were initially discussed in the field of psychology using existing psychological concepts, such discussions have become part of a multi-layered narrative with theoretical and empirical research significance (Nishida, Kubota, Tonegawa, \& Endo, 2018). A collection of concepts have emerged that have been discussed in the context of individual studies under the blanket concept of "non-cognitive skills," creating conceptual overlaps and gaps.

Heckman and Kautz (2012) called personality traits and preferences "non-cognitive skills" to distinguish them from cognitive skills. Given that non-cognitive skills have high predictive validity in economic and labor markets and are the basis for interventions in education, much attention has been given to better understanding personality traits. Subsequently, increasing discussion in the field of psychology has focused on whether personality traits, which are used as indicators of non-cognitive skills, are measurable factors that can be used to explain individuals' behaviors. Roberts $(2007,2009)$ argued that an individual's personality is a response to a situation and its analysis is possible as a stable and consistent quality that represents the individual's behavior, feelings, and thoughts. Despite ongoing debates in recent years regarding the impact of an individual's personality in any given situation, research supports the stability and consistency of personality, leading to the general acceptance of Roberts' claims.

Non-cognitive skills are generally referred to as personality traits or personality skills in studies by the OECD (2005) and other researchers (Borghans, Duckworth, Heckman, \& Weel, 2008; Tough, 2012). This terminology 
implies that personality traits or skills are in line with existing frameworks that suggest individual characteristics can be developed through educational practices (and particularly with the Big Five, which distinguishes five basic aspects of personality). Furthermore, both the OECD and Center for Educational Research and Innovation plan to conduct an international comparative study of non-cognitive skills, beginning in 2020, based on the definition of non-cognitive skills as personality traits (OECD, 2018). The Big Five has also been applied as personality traits and a measure of non-cognitive skills in previous studies, including one on the effect of university education on non-cognitive skills among students in Australia (Kassenboehmer, Leung, \& Schuler, 2018). Additionally, in a study on non-cognitive skills in adolescents, Gutman and Schoon (2013) showed that grit, self-control, and creativity have tendencies similar to personality traits, suggesting that the "skills contents" of non-cognitive skills may share commonalities with personality traits.

The use of the Big Five personality traits as a measure of non-cognitive skills had a degree of validity in previous studies. Therefore, in this study, the Big Five - as measured using the standardized FFPQ-50 for Japanese university students (see the Construction of the Short-form of the Five Factor Personality Questionnaire; Fujishima, Yamada, \& Tsuji, 2005)—was employed as a measure of non-cognitive skills.

\subsection{Physical Play in Early Childhood}

"Physical play" was defined as a general term for "play" in which children perform by vigorously moving their entire body, including their mind. The term encompasses activities conducted in nursery settings, including physical, movement, group games, and physical expression, as well as outdoor play and nature experiences. In this section, the significance of the relationship between physical play experiences in early childhood and non-cognitive skills is discussed based on the results of prior studies.

To address the decline in the level of and willingness to engage in physical activity among children, Susuki (2016) elaborated on the concept of "fully playable (Japanese: $a$-so-bi-ko-mu)" (Akita, 2009) and developed the Playability Scale of Young Children to clarify the factors that regulate "fully playable" and improve the quality of children's play. In this scale, being fully playable involves five factors: "smooth transition between reception, empathy, and reaction;" "adaptability to surroundings;" "motivation for exploration;" "creativity and imagination with focus;" and "affinity and cooperation." Thereafter, the scale was used to examine how changes in fully playable situations might improve the quality of play by using dodgeball (Suzuki \& Suzuki, 2017) and physical expression play (Susuki, 2019) during free play. Compared to traditional physical activity goals that relies on physical effects (e.g., strength and motor skills), focusing on the psychosocial aspect of "fully playable" raises the motivation for physical play activities and producing physical effects (Takenaka, 2017). Although such studies did not delve into the abilities that children acquire by entering into a "fully playable" state or the impact of such states on their lives afterward, they suggest the possibility that non-cognitive skills may result from physical activities, thereby directing future research on physical play activities.

To date, few studies have directly addressed non-cognitive skills by focusing on physical play activities during childhood. Two possible means exist for measuring the effect of specific physical activities on non-cognitive skills: using an index of non-cognitive skills and examining its relationship to 1) personality traits as non-cognitive skills or 2) physical strength/motor skills. The former approach was taken by Yamakita, Ando, Sato, Suzuki, and Yamagata (2017), who examined the relationship between the affiliation to sports clubs and the non-cognitive skill of grit (Duckworth, Peterson, Matthews, \& Kelly, 2007) in elementary school children and reported that grit was higher in children who were affiliated with sports clubs dedicated to group sports. Similarly, Nakano, Tanaka, Ikeda, and Yamauchi (2020) examined the effect of an outdoor summer camp on the personality traits of middle school students and found that the experience had a significant effect on personality traits as social and emotional skills and its degree of impact depended on participants' individual characteristics. Additionally, Ito et al. (2018) positioned safety, autonomy, creativity, cooperation, and interest as non-cognitive skills to evaluate the development of young children in play settings centered around their physicality.

Several studies have taken the latter approach of examining the relationship between physical strength and motor skills. Kasuga (2019) and Nakano (2019) both found a close relationship between physical strength and motor skills, based on the Big Five personality traits in young children. These studies were based on guardians' evaluations by proxy of non-cognitive skills and reported that fostering non-cognitive skills can have a positive effect on later physical strength improvement. Both Goto and Kasuga (2017) and Minami, Kasuga, and Goto (2019) reported that differences in physical strength and motor skills among 5-year-old girls can affect non-cognitive skills, and performing physical activities while following rules or practicing communication with multiple people increases coordination, extraversion, and integrity.

These findings suggest that non-cognitive skills may be developed through the promotion of exercise in early 
childhood. In this study, we expected that new value to children's physical play activity may be added by demonstrating the relationship between physical play experiences in childhood and non-cognitive skills, thereby filling a noted gap in the research.

\subsection{Autobiographical Memory}

The Big Five personality traits were measured for adults (i.e., university students) as non-cognitive skills fostered by the promotion of exercise in childhood. Therefore, autobiographic memory was used to examine factors related both to personality traits and to the type and content of physical play experiences in early childhood. However, memory is difficult to evaluate objectively since it is accompanied by forgetting, fluctuation, and modification and also can include various biases and rationalizations. This section discusses the validity and limitations of memory.

Almost 40 years have passed since autobiographical memory was first studied (Csikszentmihalyi \& Beattie, 1979). In developmental research, autobiographical memory is defined in episodic memory as a memory that can form one's own story that is meaningful to the story of one's life (Nelson, 1992). Singer and Salovey (1993) proposed the concept of "self-defining memory" in autobiographical memory, arguing that memory is the basis of one's self. Additionally, autobiographical memory is closely related to personal identity; i.e., a memory that symbolizes one's self. Moreover, research has demonstrated that autobiographical memories are less concerned with the accurate recall of past events than with relaying stories imbued with meaning regarding the core of one's identity (Neimeyer, \& Metzler, 1994). Since 2000, research on the function of autobiographical memory has become active, and several journals (Applied Cognitive Psychology, 2009; Memory, 2003, 2013, 2015) have continued to address the function of autobiographical memory (Bluck, 2003, 2009; Memory, 2013; Nicole \& Wang, 2015). In the process, Singer and Blago (2004) stated that autobiographical memory comprises information that has a strong connection with one's past self. In addition, Rubin, Schrauf, and Greenberg (2003) showed that there are two subjective sensations associated with the recall of autobiographical memory: the feeling of re-experiencing an event and the belief that the memory of it is correct. At present, autobiographical memory is considered to have three functions: self, direction, and society (Bluck, 2003; Sato, 2008). "Self" is the function by which memory guarantees self-consistency and maintains a favorable self-image; "direction" is a function that makes use of past problem-solving and decision-making experience; and "society" is a function that uses past experiences as a material for conversation, reminding one of relationships with people and deepening bonds with them.

Specific memories available for recall, among the vastness of past experiences, tend to have high personal significance. They reinforce a consistent sense of self and are highly likely to affect one's life going forward. Based on their analysis of the life histories of adult participants, Habermas and Bluck (2000) specifically emphasized adolescence as the period when the motivation and ability to conceptualize one's life as a consistent life story emerges. Reports suggest that humans begin recalling episodic memories with context at around four-years-old (Bruce, Phillips-Grant, Wilcox-O'Hearn, Robinson, \& Francis, 2007). Therefore, childhood memories recalled upon entering adulthood are reliable. In this study, the autobiographical memories for physical play experiences in early childhood were interpreted as "the subjective benefits" of physical play and were used as a qualitative measure.

Conversely, research relying on autobiographical memories becomes a cross-sectional retrospective study owing to the research methods employed. Measurement accuracy tends to be relatively low in such studies compared to intervention and prospective cohort studies. Specifically, bias regulation (the confounding factor) will impact personality traits relative to the relationship between the causal variable of physical play experiences in early childhood and the resultant variable of personality traits in adulthood. Given that it is difficult to determine confounding factors that indirectly influence personality traits, the factors and degree of influence cannot be clarified. Furthermore, although it may be possible to clarify the existence of the relationship and trend between physical play experiences in early childhood and the resultant personality traits in adulthood, the limitations of this study prohibit a description of their level, degree, or causality. To address these limitations, longitudinal prospective studies are required. Therefore, this study should be considered a pilot study, with an objective of furthering the direction of future research; specifically, it examines the cohorts to be used as participants and factors to be measured and presents the resulting perspectives.

\section{Objectives}

The ultimate goal of this study was to clarify the determinants and mechanisms involved in the development of non-cognitive skills in physical play experiences in early childhood. As the first stage of the larger study, the following smaller studies were conducted to verify that physical play experiences in early childhood impact 
non-cognitive skills.

Study I aimed to determine the physical play experiences in early childhood and the degree that such experiences affected non-cognitive skills in adulthood. Using a quantitative approach, the effect was analyzed and examined using structural equation modeling (SEM). In Study II, the quantitative confluent relationships obtained in Study I were qualitatively visualized. The autobiographic memory of physical play activities in early childhood was treated as a "subjective benefit" of physical play, and its relationship to non-cognitive skills was analyzed using co-occurrence network analysis.

This study was a mixed-methods study consisting of an explanatory sequential design (Teddie, \& Tashakkori, 2009) and connects the individual experiences and stories detailed in Study II to the statistical results obtained in Study I. In both cross-sectional retrospective studies, it was difficult to establish the confounder in retrospect, when compared to longitudinal prospective studies. Therefore, a major shortcoming of the study is its difficulty in determining bias regulation. However, to satisfy the urgent need for evidence related to this particular topic within the early childhood education field, this study attempted to provide at least some evidence on non-cognitive skills despite this noted challenge.

\section{Methodology and Procedure}

\subsection{Study I}

Study I utilized the quantitative approach of SEM to investigate the degree that physical play experiences in early childhood influence non-cognitive skills in adulthood.

Table 1. Average value and standard deviation of scores related to experience of play in childhood

\begin{tabular}{lll}
\hline Elements & Item & $M(S D)$ \\
\hline Type (active) & & $3.19(0.79)$ \\
\hline Play using large equipment & Gymnastic bar, Monkey bar, Climbing bar & \\
& Jungle gym, Slide & \\
& Exercise mat, Vaulting box & \\
& Large building blocks & $3.66(0.87)$ \\
\hline Game activities & Running, Relay & \\
& Tag & \\
& Musical chairs, Drop the handkerchief & \\
\hline Formative play & Collect and throw stones, raw letters, and pictures using stones & $3.08(091)$ \\
& Walk on the ground barefoot, Play with mud & \\
& Play in the rain, Play throwing water at each other & \\
& Collect and make something with grass/flowers/ berries & $2.71(1.12)$ \\
& Catch insects and fish, breed insects and animals & \\
\hline Play involving interaction & Game of Sumo and wresting & $2.93(1.03)$ \\
\cline { 2 - 4 } & Bird in the cage, Oshikura manju & $3.25(0.80)$ \\
\hline Play using small equipment & Bicycle, pushing car, Cart, Bicycle & \\
\hline Play using a toy vehicle & Stilts & \\
\hline Motivation (Fully playability) & & Enjoys meeting new things, people, and ideas \\
\hline Adaptability to surroundings & Finds renewed interest in familiar things, people, and ideas & \\
\hline Affinity and cooperation & Enjoys competition and winning/losing & \\
& Creates rules and plans to reach a goal \\
& Fakes part in serious discussion to share ideas and challenges & \\
\hline
\end{tabular}


with others

Invites others to join in and organizes groups

Others are naturally caught up in the child's play

Smooth transition between Listens to advice and opinions of others reception, empathy and Acknowledges and adopts ideas of others reaction

Encourages, teachers, and praises others

Thinks and acts based on good understanding of motives and feelings of others

Has fun with and blends in with others while sharing goals, experiences, and ideas

Creativity and imagination Exercises ingenuity and makes suggestions to realize one's $2.90(0.87)$ with focus ideas

Recalls past experience and applies it to current play

Makes good use of materials and resources through trial and error

Does not give up until reaching a certain level of fulfillment

Sets or chooses challenging tasks

Attempts to follow through without help

Decides own role and carries it out responsibly

Tries to motivate him/herself

\section{Characteristics}

\begin{tabular}{|c|c|c|}
\hline \multirow[t]{3}{*}{ Aggressive } & Voluntarily take part in activities using the body & $3.57(0.90)$ \\
\hline & Enthusiastically try challenging activities & \\
\hline & Willingly take part in group activities and competition & \\
\hline \multirow[t]{6}{*}{ Active } & Played while standing more than sitting & $3.71(0.84)$ \\
\hline & Sweated a lot during play & \\
\hline & Made large and bold movements while playing & \\
\hline & Liked to play using the body actively & \\
\hline & Used to go from one play structure to another & \\
\hline & Played without worrying about one's clothes getting dirty & \\
\hline \multirow[t]{3}{*}{ Social } & Played while being involved with friends & $3.79(0.75)$ \\
\hline & Voluntarily joined others' play & \\
\hline & Watch and often mimicked children around me & \\
\hline Open & Played tag, ball games, and jumping rope in a wide space & $4.22(0.87)$ \\
\hline \multicolumn{3}{|l|}{ Location } \\
\hline Nature space & Caves and banks & $3.67(0.87)$ \\
\hline Nature experience space & Camping, hiking, and mountain climbing space & $2.44(0.87)$ \\
\hline Hiding space & Secret base & $2.68(1.37)$ \\
\hline Anarchy space & Storage space, Construction sites & $1.84(1.14)$ \\
\hline \multicolumn{3}{|l|}{ Type (static) } \\
\hline Sand play & Making mountains, rivers, and tunnels with sand & $2.63(1.50)$ \\
\hline Play fighting & Pretending to be a TV hero or character & $2.12(1.35)$ \\
\hline Rhythm play & Danced and played to music and rhythm & $1.91(1.20)$ \\
\hline
\end{tabular}


Table 2. Average value and standard deviations of scores related to non-cognitive skills (Five Factor Personality Questionnaire for internal consistency)

\begin{tabular}{|c|c|c|}
\hline & Items Domains & $M(S D)$ \\
\hline & Extraversion & Introversion \\
\hline$\overline{E X 1}$ & Activity & $6.35(1.73)$ \\
\hline EX2 & Dominance & $5.54(1.86)$ \\
\hline$\overline{\text { EX3 }}$ & Gregariousness & $6.42(1.85)$ \\
\hline EX4 & Excitation-seeking & $6.29(1.77)$ \\
\hline \multirow[t]{2}{*}{ EX5 } & Attention-getting & $6.46(1.51)$ \\
\hline & Attachment & Separateness \\
\hline $\mathrm{A} 1$ & Warmth & $7.31(1.47)$ \\
\hline A2 & Cooperativeness & $7.41(1.33)$ \\
\hline A3 & Trustfulness & $6.28(1.74)$ \\
\hline$\overline{\mathrm{A} 4}$ & Understanding & $7.49(1.39)$ \\
\hline \multirow[t]{2}{*}{$\mathrm{A} 5$} & Respect for others & $7.17(1.55)$ \\
\hline & Controlling & Naturalism \\
\hline $\mathrm{C} 1$ & Meticulousness & $5.88(1.76)$ \\
\hline $\mathrm{C} 2$ & Persistence & $6.28(1.79)$ \\
\hline $\mathrm{C} 3$ & Responsibility & $7.23(1.59)$ \\
\hline $\mathrm{C} 4$ & Self-control & $5.46(1.56)$ \\
\hline \multirow[t]{2}{*}{$\mathrm{C} 5$} & Deliberateness & $6.40(1.67)$ \\
\hline & Emotionality & Unemotionality \\
\hline Em1 & Anxiousness & $6.78(1.85)$ \\
\hline Em2 & Tension & $7.38(1.82)$ \\
\hline Em3 & Depressiveness & $5.48(1.90)$ \\
\hline Em4 & Self-criticism & $5.83(2.00)$ \\
\hline \multirow[t]{2}{*}{ Em5 } & Mood fluctuation & $7.16(2.02)$ \\
\hline & Playfulness & Practicality \\
\hline $\mathrm{P} 1$ & Curiousness & $7.09(1.42)$ \\
\hline $\mathrm{P} 2$ & Imaginativeness & $5.95(1.68)$ \\
\hline P3 & Artisticness & $6.02(2.09)$ \\
\hline $\mathrm{P} 4$ & Inner sensibility & $7.29(1.31)$ \\
\hline P5 & Rigidity & $6.63(1.83)$ \\
\hline
\end{tabular}

\subsubsection{Participants}

Surveys were collected from 677 university students. Valid answers were obtained from 607 university students in Japan (aged 18-26 years; 8 universities, 10 faculties, 22 departments; 380 women and 227 men).

\subsubsection{Contents of Questionnaire Survey}

1) Physical play experiences in early childhood consisted of four elements-Types, Characteristics, Motivation ("full playability"), and Location - that were adopted based on existing scales, classification schemes, and theories. Participants rated their reflections of early childhood for each item using a five-point Likert-type scale that ranged from 1 (never) to 5 (very often). The initial 27 items ( 74 sub-items) for physical play experiences in early childhood were subjected to factor analysis (maximum likelihood method), leading to the latent variables 
being reorganized as 5 factors of 22 items ( 58 sub-items) (see Table 1).

2) Big Five personality traits (non-cognitive skills) were evaluated with the FFPQ-50, which consisted of 50 five-factor items (see Construction of the Short-form of the Five Factor Personality Questionnaire; Fujishima et al., 2005). Responses ranged from 1 (strongly disagree) to 5 (strongly agree). The FFPQ-50 is compliant with other global and standard personality tests that utilize the five-factor model, such as the NEO Personality Inventory (Costa \& McCrae, 2008), but was specifically designed to reflect a Japanese understanding of personality. The scale quantifies five so-called "super traits"-Extraversion, Attachment, Controlling, Emotionality, and Playfulness - each consisting of five component traits (25 total; Table 2). Before the SEM analysis, FFPQ-50 items with a factor loading $<0.5$ were excluded from the model.

\subsubsection{SEM Data Analysis}

The degree that a person's physical play experiences in early childhood influenced their non-cognitive skills in adulthood was examined using SEM, based on our hypothesized model. Excel software was used for statistical analysis.

\subsection{Study II}

Study II utilizes a qualitative approach to connect physical play experiences during early childhood (recounted as autobiographical memories) to specific subjective benefits in adulthood (in the form of enhanced non-cognitive skills) using co-occurrence network analysis.

\subsubsection{Participants}

Surveys were collected from 202 students (valid response rate $=100 \%$; aged 18-26 years; 7 universities, 10 faculties, 26 departments; 129 women and 93 men).

\subsubsection{Questionnaire Survey Contents}

1) Participants recounted episodes involving their physical play experiences in early childhood in an open-ended format. The instructional prompt read as follows: "Please recount any physical play experiences in early childhood (i.e., nursery school, kindergarten, or early elementary school age) that have stayed with you to this day. For each, what kind of game or activity was it? How did you do it? What are your memories of it? How did you feel about it, and yourself, as you engaged in it? What kind of effects do you feel the experience has had on you to this day? Please express yourself freely."

2) Non-cognitive skills in adulthood (i.e., at university age) were measured using four question items, corresponding to the four Big Five personality traits measured on the FFPQ-50, which achieved significant path coefficients in the model tested in Study I: i.e., Extraversion vs. Introversion, Attachment vs. Separateness, Controlling vs. Naturality, and Playfulness vs. Practicality. Participants rated themselves in each dimension on a six-point Likert scale that ranged from 6 (very extroverted) to 1 (very introverted) based on their current personality as an adult university student.

\subsubsection{Data Analysis for Text Mining Using KH Coder}

Data were analyzed by text mining using KH Coder (Higuchi, 2014a, 2014b) statistical software. Text mining is a collection of analytic methods often employed in qualitative research to systematically process, quantify, and visualize textual information. This approach was utilized because it allows qualitative text data to be treated similarly to numerical data and can reduce the analyst's bias.

Specifically, analysis was conducted according to the following procedure:

1) Participants' written responses detailing the subjective benefits of their physical play experiences in early childhood were converted into digital text data.

2) All text data were morphologically parsed using ChaSen software. The resulting data were cleaned as follows: I. Words that imply the prompt itself (e.g., "remember" and "memory"), and words without a clear meaning in isolation were not extracted. II. Some words (e.g., "climbing pole" and "tag" (Japanese: oni-asobi) were manually extracted as compound words. III. Synonymous words were collapsed into a single term.

3) Morpheme analysis was conducted via text mining.

4) Co-occurrence network analysis can be used to visualize associations between words in a dataset and was conducted to visualize the associations between words and non-cognitive skills (personality traits). Co-occurrence networks represent words as circles ("nodes"), whose size corresponds to their usage frequency in the dataset. Word pairs that "co-occur"-i.e., appear in similar contexts or locations - are connected by a line ("edge"). The strength of an association is represented by the thickness of the edge, rather than the relative 
position of nodes in the visual space. In addition, the overall density of the network can be expressed using the Jaccard index.

5) The resulting quantitative findings were then considered with respect to autobiographical episodic memories in a qualitative manner.

\subsection{Ethical Considerations}

These surveys were conducted under the Aichi University of Education Code of Ethics. The aims and reach of this study were explained to the participating students and their written consent was secured. Thorough ethical considerations were taken, and it was ensured that no individuals could be identified from the research. Participants were informed that participation was voluntary.

\section{Results}

\subsection{Study I}

\subsubsection{SEM Results}

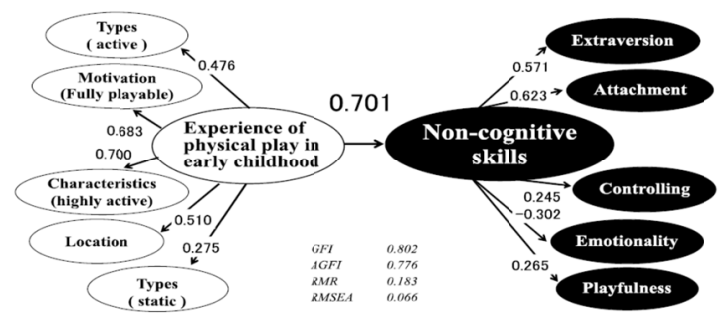

Figure 1. Analysis 1: The relation between overall factors of play experience and overall factors of non-cognitive skills

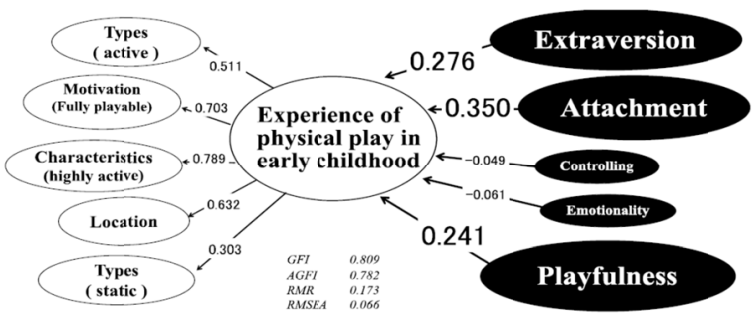

Figure 2. Analysis 2: The relation between overall factors of play experience and each latent variable of non-cognitive skills

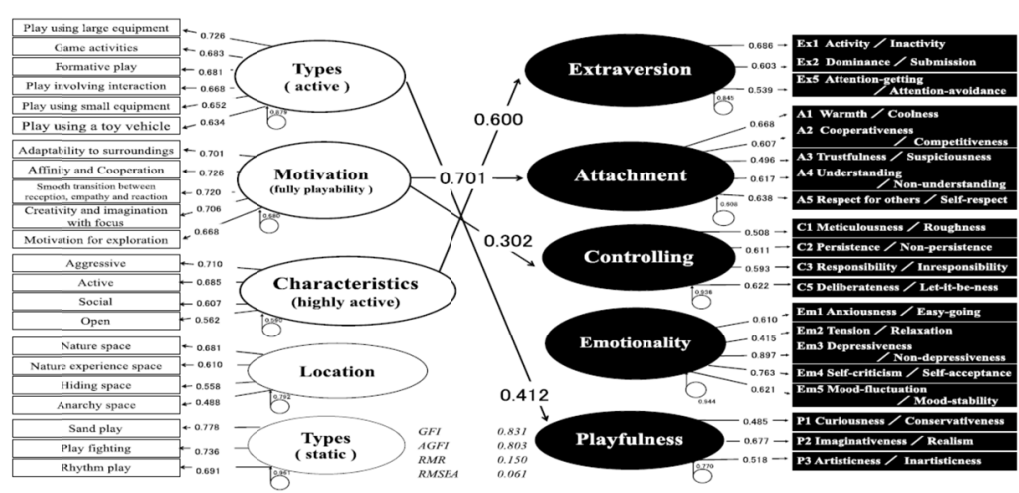

Figure 3. Analysis 3: The relation between latent variables of each play experience and latent variables of non-cognitive skills

GFI: Goodness of Fit Index; AGFI: Adjusted Goodness of Fit Index

RMR: Root Mean square Residual; RMSEA: Root Mean Square Error of Approximation 
The effects of physical play experiences in early childhood on non-cognitive skills in adulthood were analyzed using SEM in three parts.

1) First, the relationship between the overall factors of physical play experiences and the overall factors of non-cognitive skills was analyzed. The path coefficient from physical play experiences in early childhood to non-cognitive skills was high (0.701; Figure 1$)$.

2) Second, the relationship between the overall factors of physical play experiences in early childhood and each latent variable of non-cognitive skills was analyzed (Figure 2). The overall factors of physical play experiences in early childhood had the strongest effect on "Attachment" with a path coefficient of 0.350 , followed by "Extraversion" (0.276) and "Playfulness" (0.241).

3) Finally, the relationship between the latent variables of each physical play experience in early childhood and the latent variables of non-cognitive skills was analyzed. Physical play experiences in childhood had effects on the latent variables of non-cognitive skills. The strongest positive association observed was between Motivation ("full playability") and Attachment (0.701), followed by Characteristics ("highly active") vs. Extraversion (0.611), Type ("active") vs. Playfulness (0.412), and Motivation ("full playability") vs. Controlling (0.312). The model had inadequate goodness-of-fit $(\mathrm{GFI}=0.831$, AGFI $=0.803$, RMR $=0.150$, RMSEA $=0.061)$, perhaps because many of the sub-items were excluded when the variables were reorganized before testing. However, some of this lack of fit might be forgivable since the model purports to describe relationships based on childhood recollections, a bias-prone metric that is difficult to control for.

\subsubsection{Discussion}

The experience of being "fully playable" has a strong effect on the personality traits of attachment (warmth, cooperativeness, trustfulness, empathy, respect for others) and controlling (meticulousness, persistence, responsibility, self-control, deliberateness). Further, the difficulty and variety of play has an effect on the personality traits of extraversion (activity, dominance, gregariousness, excitation-seeking, attention-getting) and playfulness (curiousness, imaginativeness, inner sensibility, rigidity). The results showed a correlation between sufficiently rich physical play experiences and the personality trait of attachment as an adult. A correlation between a high level of activeness during play and the trait of extraversion was also found.

\subsection{Study II}

In total, 349 episodes were recounted (average $=1.7$ per participant). Text mining extracted a total of 43,545 words: 14,427 words excluding commonly used words such as particles and auxiliary verbs, 3,693 unique words, and 3,315 words used.

\subsubsection{Results: Words Characterizing the Subjective Benefits of Physical Play Experiences in Early Childhood}

Table 3. Words characterizing the subjective benefits of physical play experiences in early childhood

\begin{tabular}{|c|c|c|c|c|c|c|c|c|c|}
\hline \multicolumn{2}{|l|}{ Age } & \multicolumn{2}{|c|}{ When } & \multicolumn{2}{|l|}{ Place } & \multicolumn{2}{|c|}{ People } & \multicolumn{2}{|l|}{ Objects } \\
\hline morpheme & $\begin{array}{l}\text { Number of } \\
\text { episodes }\end{array}$ & morpheme & $\begin{array}{l}\text { Number of } \\
\text { episodes }\end{array}$ & morpheme & $\begin{array}{l}\text { Number of } \\
\text { episodes }\end{array}$ & morpheme & $\begin{array}{c}\text { Number of } \\
\text { episodes }\end{array}$ & morpheme & $\begin{array}{c}\text { Number of } \\
\text { episodes }\end{array}$ \\
\hline elementary school & 81 & every day & 43 & my neighborhood & 71 & friend & 204 & playground equipment & 46 \\
\hline kindergarten & 77 & time & 35 & park & 67 & alone & 52 & sand & 23 \\
\hline day nursery & 66 & gloomy & 30 & home & 45 & mother & 41 & ball & 34 \\
\hline lower grade of elementary school & 59 & & & schoolyard & 29 & teacher & 40 & mud & 27 \\
\hline five-year-olds & 24 & & & outside & 26 & boy & 29 & iron bar & 26 \\
\hline \multirow[t]{6}{*}{ my childhood } & 19 & & & playground & 24 & father & 25 & tree & 21 \\
\hline & & & & inside in my house & 20 & neighbor & 24 & jungle gym & 20 \\
\hline & & & & sandbox & 17 & girl & 24 & hands & 20 \\
\hline & & & & & & pair & 23 & mountain & 19 \\
\hline & & & & & & child & 23 & unicycle & 19 \\
\hline & & & & & & & & rope & 19 \\
\hline \multicolumn{2}{|l|}{ Things } & \multicolumn{4}{|c|}{ Action } & \multicolumn{4}{|c|}{ Emotions } \\
\hline morpheme & $\begin{array}{l}\text { Number of } \\
\text { episodes }\end{array}$ & morpheme & $\begin{array}{l}\begin{array}{l}\text { Number of } \\
\text { episodes }\end{array} \\
\end{array}$ & morpheme & $\begin{array}{l}\begin{array}{c}\text { Number of } \\
\text { episodes }\end{array} \\
\end{array}$ & morpheme & $\begin{array}{c}\begin{array}{c}\text { Number of } \\
\text { episodes }\end{array} \\
\end{array}$ & morpheme & $\begin{array}{c}\text { Number of } \\
\text { episodes }\end{array}$ \\
\hline $\operatorname{tag}$ & 91 & create & 48 & go out & 25 & like & 131 & specifically & 23 \\
\hline playing outside & 50 & tell & 48 & go home & 25 & fun & 113 & angry & 21 \\
\hline practice & 35 & go & 47 & hold & 23 & together & 80 & high & 20 \\
\hline dodgeball & 33 & use & 43 & run around & 21 & many & 68 & frustrate & 19 \\
\hline exercise & 30 & move & 41 & hedge & 21 & a lot & 39 & strong & 19 \\
\hline $\operatorname{legs}$ & 28 & run & 38 & get together & 19 & love & 33 & competitive & 19 \\
\hline pretend play & 21 & feel & 36 & come & 19 & enjoy & 28 & pretty & 18 \\
\hline hide and seek & 21 & think & 35 & cry & 18 & close & 28 & feeling & 16 \\
\hline baseball & 21 & watch & 33 & gather & 18 & good at & 28 & early & 15 \\
\hline soccer & 21 & join & 32 & go on & 16 & absorb & 26 & unpleasant & 14 \\
\hline rule & 16 & climb & 27 & teach & 15 & focus & 24 & dislike & 14 \\
\hline
\end{tabular}


Table 3 lists some of the words participants used to characterize the subjective benefits of their physical play experiences in early childhood, according to their rank and frequency in recounted autobiographical episodes.

Words were divided into eight semantic categories: Age, When, Places, People, Objects, Things, Actions, and Emotions. The most frequently mentioned words in each category are shown. The most common word across all categories was "friend[s]" (People), mentioned 204 times in total, followed by "like" (Emotions: 131), "fun" (Emotions: 113), “tag” (Things: 91), and “[my] neighborhood” (Places: 71).

\subsubsection{Associations Between Non-cognitive Skills and Physical Play Experiences in Early Childhood}

Associations were explored between students' self-ratings for current Extraversion-Introversion, AttachmentSeparateness, Controlling-Naturality, and Playfulness-Practicality (Table 4), and the language they used when recounting their physical play experiences in early childhood. Figures 4-8 show co-occurrence networks of words having strong associations with self-assessed scores for these traits, which appeared at least 15 times in the dataset. Thereafter, using the Key-Word-In-Context Concordance tables, the usage of these words was explored in the context of surrounding text, and the original texts referred to repeatedly, to generate qualitative explanations of the associations observed.

Table 4. Self-evaluation of some big five personality traits (numbers, means, and standard deviations)

\begin{tabular}{llllllllll}
\hline Big Five & 6 & 5 & 4 & 3 & 2 & 1 & Big Five & Mean & SD \\
\hline $\begin{array}{l}\text { Personality } \\
\text { traits }\end{array}$ & Very & Moderately & Slightly & Slightly & Moderately & Very & $\begin{array}{l}\text { Personality } \\
\text { traits }\end{array}$ & \\
\hline Extraversion & 45 & 63 & 69 & 92 & 54 & 26 & Introversion & 3.64 & 1.46 \\
\hline Attachment & 15 & 55 & 75 & 106 & 72 & 26 & Separateness & 3.30 & 1.28 \\
\hline Controlling & 22 & 85 & 80 & 78 & 70 & 14 & Naturality & 3.62 & 3.94 \\
\hline Playfulness & 27 & 74 & 95 & 94 & 43 & 16 & Practicality & 3.71 & 1.27 \\
\hline
\end{tabular}

1) Extraversion vs. Introversion (Figure 4)

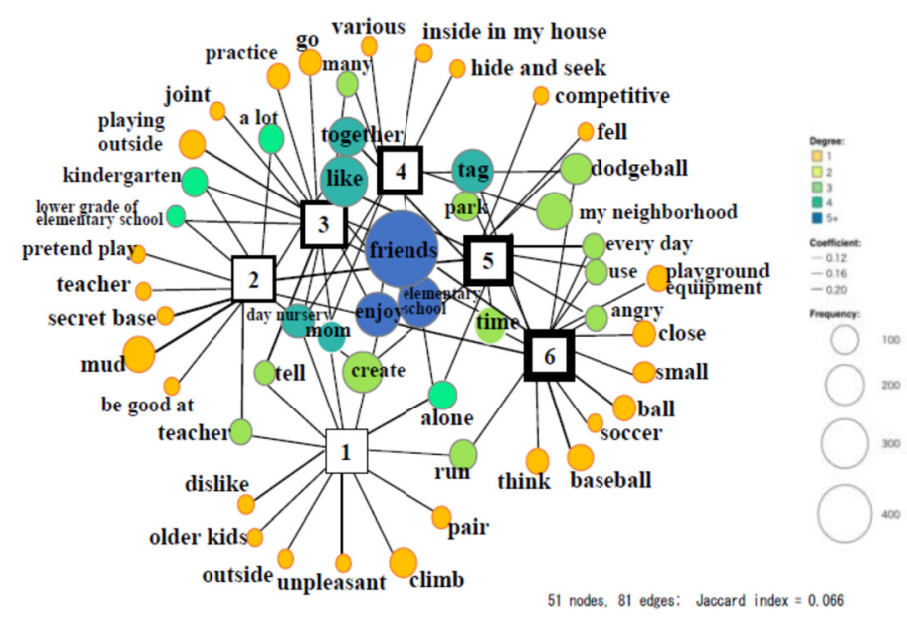

Figure 4. Network of extracted terms associated with extraversion vs. introversion

High self-rated Extraversion was strongly associated with the usage of language such as "friends," "soccer," "baseball," "ball," "tag," "play equipment," and "daily" when recounting autobiographical memories. These qualities are well illustrated by the following autobiographical memory: "I would play baseball, soccer, dodgeball, and tag with my older brother and other older kids I was friends with." In contrast, high self-rated Introversion as an adult was strongly associated with language such as "mud," "alone," and "dislike." For 
example, these participants' accounts tended to resemble the following: "I usually played together with my sibling or by myself silently, rather than outside."

2) Attachment vs. Separateness (Figure 5)

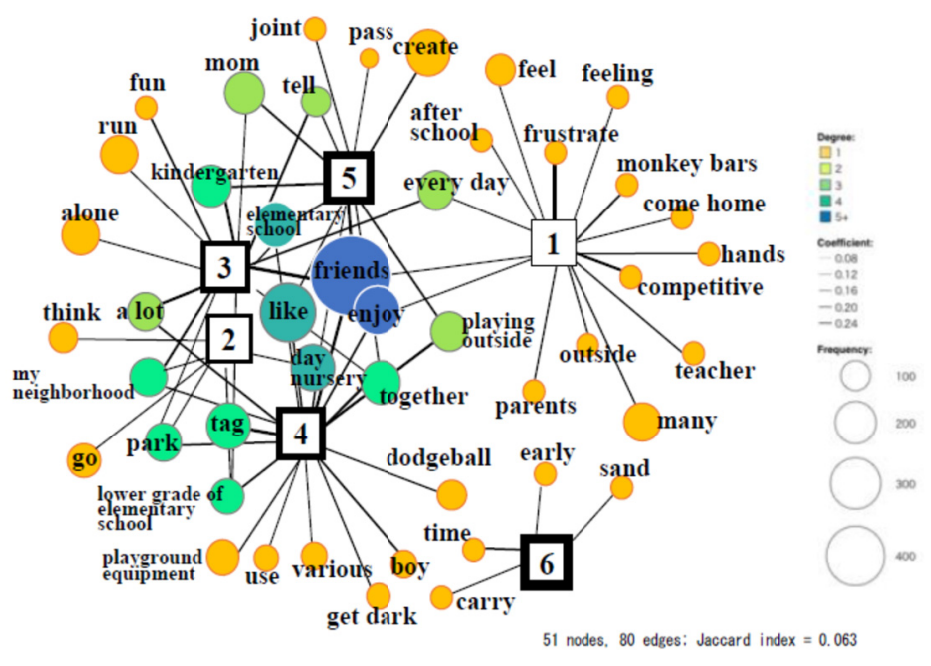

Figure 5. Network of extracted terms associated with attachment vs. separateness

High self-rated Attachment was strongly associated with the usage of language such as "friends," "sand," "create," and "playing outside." These qualities are well illustrated by the following autobiographical memory: "I had so much fun playing outside with my friends, playing tag, or playing in the sand." In contrast, high self-rated Separateness as an adult was strongly associated with language such as "monkey bars," "competitive," and "frustrating." For example, these participants relayed experiences such as the following: "I never give up. I hated the fact that I couldn't do the monkey bars; so I would practice until my parents came calling - so much that my hands hurt."

3) Controlling vs. Naturality (see Figure 6)

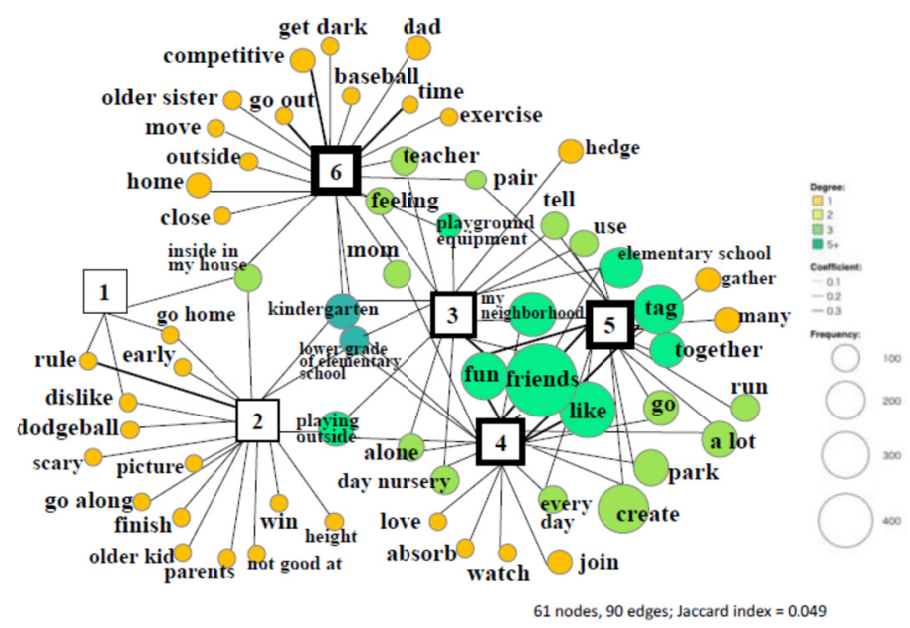

Figure 6 . Network of extracted terms associated with controlling vs. naturality

High self-rated controlling was strongly associated with the usage of language such as "time," "outside," "get dark," and "competitive." These qualities are well illustrated by the following autobiographical memory: "I was super competitive. I would forget the time when I played baseball with my dad and good friends, until it got 
dark...I had so much fun playing outside with my friends, playing in the sand and tag." In contrast, high self-rated naturality as an adult was strongly associated with language such as "rules," "go out," and "dislike." For example, these participants relayed experiences such as the following: "I'd go out to play as soon as I got home. We liked games where we could change the rules ourselves. Dodgeball was scary."

4) Playfulness vs. Practicality (see Figure 7)

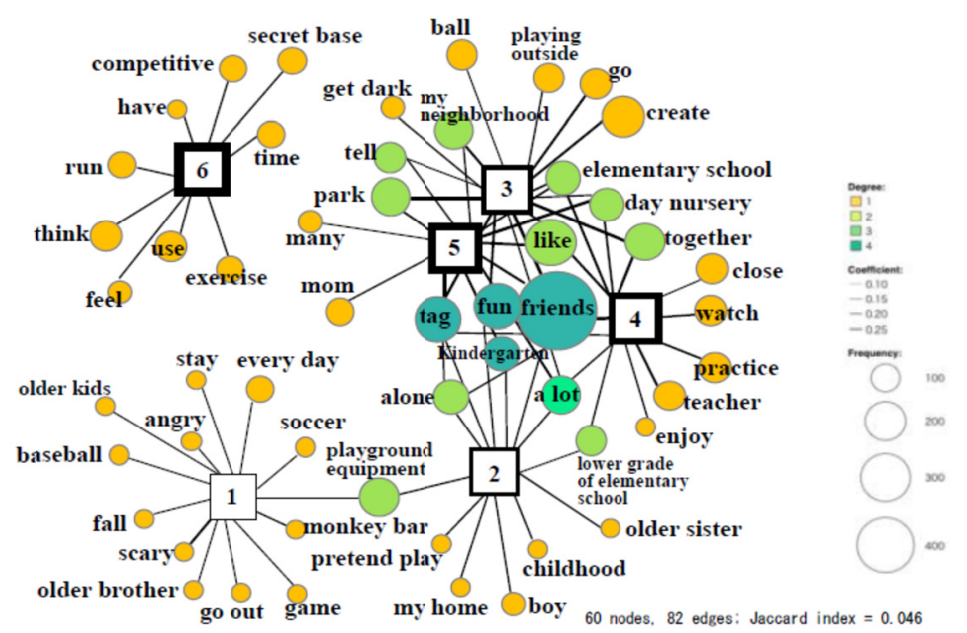

Figure 7. Network of extracted terms associated playfulness vs. practicality

High self-rated playfulness was strongly associated with the usage of language such as "secret base," "have," "compete," "exercise," and "friend." These qualities are well illustrated by the following autobiographical memory: "My friends and I would pretend to have a secret base; we'd bring in stuff and be thinking about how to use it. It was fun to compete with each other, too." In contrast, high self-rated practicality as an adult was strongly associated with language such as "baseball," "game," and "scared." For example, these participants relayed experiences such as the following: "Nearly every day, I played soccer, baseball, and other games together with older children and my big brother."

\section{General Discussion and Conclusion}

This study investigated the hypothesis that physical play experiences in early childhood affect the subsequent development of non-cognitive skills using both qualitative and quantitative approaches, primarily focusing on the subjective benefits of said experiences apparent in the autobiographical memories of university students. SEM was utilized to quantify associations between latent variables for physical play experiences in early childhood and a variety of latent variables for non-cognitive skills. Thereafter, text mining was utilized to analyze 349 written accounts of autobiographical episodes, to identify and explicate specific characteristics of the physical play experiences in early childhood based on memories. Co-occurrence network analyses were used to visualize the relationships between participants' non-cognitive skills as adults - as represented by self-rated personality traits - and elements of their autobiographical memories of physical play experiences in early childhood. Below are the characteristic findings that were visualized.

(1) Participants who self-rated "attachment" highly as a personality trait possessed autobiographical memories of physical play in early childhood concerning the fun of playing outdoors with their friends and the various contrivances made to enhance such play. Individuals who scored high on attachment demonstrated the unique characteristic of being flexible toward interpersonal relationships and distances (The Society for FFPQ's Research, 2002, p. 6). Individuals who possessed such characteristics perceived their experiences of physical play in early childhood, experiences such as having become absorbed in play; having cooperated, sympathized, and shared with others; and having respected others through group play such as playing tag, as having benefited their own attachment. Aside from a personality trait, Endo (2020) defines attachment as (a) the tendency for a person, when encountering a crisis and experiencing fear, anxiety, and other negative emotions, to strongly want to become attached to, or stay physically close to, a specific person, in both the physical and psychological sense, combined with a tendency to act in ways to become attached to, or stay physically close to, such a person; and (b) engaging in behaviors that result in the formation of a circle of reassurance and a sense of security. The quality 
of attachment is linked to the development of diverse non-cognitive skills, and the perspective of individual development, of encountering different sorts of people and accumulating different sorts of experiences, is essential (Vaughn \& Bost, 1999). Moreover, in early childhood, play that involves numerous other people is understood to affect the development of attachment. As seen in this study, attachment is fostered over a long period up to adulthood. Therefore, future studies should investigate not only the factors that mediate attachment but also models that incorporate adjustment factors in a complex manner (Kabaya, 2017).

In contrast, participants who self-rated "separateness" highly as a personality trait cited autographical memories with experiences in which they sought to maintain high self-esteem, hated to lose, and became absorbed in honing their skills in isolation. Although their experiences differed from those described in the "attachment" cases, those closer to the separateness pole of Separateness-Attachment are said to demonstrate interpersonal separation and individuality (The Society for FFPQ's Research, 2002, p. 6). Moreover, the commonality between separation and individuality tended to be high.

(2) Participants who self-rated "extraversion" highly as a personality trait possessed autobiographical memories of their devotion to play, characterized by vigorous physical activity that was performed in groups with older siblings and other children. Extraversion indicates proactiveness in interpersonal relationships as well as the tendency to seek intense stimulation and risk (The Society for FFPQ's Research, 2002, pp. 4-5). Individuals who possess such qualities often talk about their active experiences encountered through baseball, soccer, and other games; their experiences of having played gregariously in groups; and of having pursued excitement. In contrast, participants who self-rated "introversion" highly characteristically recalled, as autobiographical memories, their experiences of "having played quietly indoors rather than outdoors" and "being alone or with brothers/sisters, instead of with many people."

(3) Many participants who self-rated "controlling" highly as a personality trait possessed autobiographical memories of having become immersed in organized play outdoors with friends and their fathers, although they hated to lose. The fact that these participants often talked about their experiences of physical play in early childhood; of systematic, organized, and physical play that they felt comfortable with and regarded as a benefit, coincided with the controlling pole in personality traits, where people can consciously and purposively control the self and the environment. In contrast, participants who rated "naturality" highly as a personality trait possessed autobiographical memories of preferring the kinds of play where they could change the rules themselves. Those who are closer to the naturality pole reportedly do not try to artificially control their environment but instead respect natural frameworks (The Society for FFPQ's Research, 2002, pp. 6-7). The fact that these participants talked about their experiences of preferring loose rules and playing haphazardly, non-competitively, and flexibly is thought to have commonality, as with "controlling" types, with their current personality traits and interest in the quality of experiences.

(4) Participants who self-rated "playfulness" highly as a personality trait possessed autobiographical memories of the fun and excitement, creating "hideouts" or "forts" with their friends, and competing among themselves to make things. Compared with the play experiences seen with the other personality traits, many of these individuals were more imaginative and freewheeling. They talked about innovative and enterprising pleasures. Those close to the playfulness pole are said to show a tendency to give themselves over to overflowing abundance and transcend play to out-of-the-ordinary experiences (The Society for FFPQ's Research, 2002, p. 8). They showed a tendency to overlap the current self with these autobiographical memories. In contrast, participants who self-rated "practicality" highly showed a tendency to have had the experience, as an autobiographical memory, of immersing themselves in ball games that they played together with older children and older brothers. Those close to the practicality pole reportedly show a tendency to be steadfast and carry out actions without becoming bogged down in emotions (The Society for FFPQ's Research, 2002, p. 9). However, although not as typical as those seen in the memories of playfulness, participants showed a tendency to talk about play that was steadfast, conservative, organized, and disciplined.

In summary, participants showed a tendency to talk about characteristic experiences of physical play in early childhood that had different tendencies according to both their personality trait factors and the opposite poles of each trait. Simultaneously, commonality was seen between a personality trait as one's current non-cognitive skills and the relationship with the quality perceived within their play. In other words, it became possible to identify the aspect of the participants perceiving specific subjective benefits derived from the play that they experienced in early childhood.

Barclay and Subramaniam (1987) revealed that an individual's personality affects the events that he/she recalls, the events that coincide with the personality of the recaller are more liable to be recalled, and the events are 
liable to be reorganized to fit his/her self-schemata. Moreover, Cappeliez, O'Rourke, and Chaudhury (2005) as well as Cully, LaVoie, and Gfeller (2001) stated that the recall function for autobiographical memories is related to one's personality traits, sense of happiness, and degree of satisfaction with one's life, and is linked to the self in different forms. As to the question of what the assessment of one's personality traits is based on, the researchers cite the experiences that participants recalled as an example. As stated by Ota (2009), the content of past experiences recalled by university students is closely related to the formation and transformation of self-concept; thus, such content affects their personality traits.

Given that the quality of physical play experiences in early childhood, used in this study as autobiographical memories, showed a tendency to have a commonality with personality traits, supports the hypotheses of this study that (1) a relationship exists between the factors that form personality traits and the experiences of physical play in early childhood; and (2) despite the bias owing to various factors found both inside and outside the individual at that particular timepoint, as well as the time leading up to it, experiences of physical play in early childhood had an influence on adults. Our findings also suggest that experiences of physical play in early childhood affect the development of non-cognitive skills.

\section{Limitations and Challenges}

This study had the following limitations and challenges. First, although the hypothesis that physical play experiences in early childhood affect the development of non-cognitive skills was supported, the evidence did not sufficiently illustrate what or how many physical play experiences were engaged in by the participants.

Second, from a methodological point of view and based on the first limitation, it was necessary to remove the influence of incentive and culture, which are other key factors that can modify behaviors, when analyzing the effect of personality on the behavior of individuals. However, distinguishing the effect of non-cognitive skills from incentives and motivations, which differ depending on the situation, was challenging, and the controls for doing so were insufficient in this study. Simultaneously, this was a limitation related to having used autobiographic memories as data. Despite these limitations, the presence of a relationship was investigated, first using quantitative analysis and then through qualitative analysis of participants' free-writing samples regarding subjective benefits. The significance of this study was confirmed; it visualized an interrelationship between physical play experiences in early childhood and the development of non-cognitive skills through the employment of the text mining method. This method was used to remove the complexity of individual qualitative data as well as the arbitrariness of the researchers.

Third, the study enrolled only university students between the ages of 18 and 26 years. Children's play styles continue to evolve: video games were invented in the 1970s, which were typically played while seated. The subjective benefits of physical play, and how individuals self-appraise non-cognitive skills, likely depends on their generation. Future studies could be enhanced by adding a cross-sectional survey component, to narrow down the beliefs and participants to be analyzed.

Ultimately, a positive longitudinal prospective investigation is required. However, this study was able to acquire suggestive viewpoints and narrow down the relationship between personality traits as non-cognitive abilities and physical play experiences in early childhood that may enable the execution of a study. In the future, the authors would like to continue research in this area to contribute to further knowledge regarding the development of non-cognitive skills and the development of intervention programs to promote them.

\section{Acknowledgments}

This work was supported by the Japan Society for the Promotion of Science, KAKENHI Grant Number 17K01633.

\section{References}

Akita, K. (2009). Hoiku-no-kokoromochi, Essays on early childhood education and nursery (pp. 24-25). Nagoya, JPN: Hikarino Kuni.

Barclay, C. R., \& Subramaniam, G. (1987). Autobiographical memories and self-schemata. Applied Cognitive Psychology, 1(3), 169-182. https://doi.org/10.1002/acp.2350010303

Bluck, S. (2003). Special issue: Autobiographical Memory: Exploring its functions in everyday life. Memory, 11(2), 113-123. https://doi.org/ 10.1080/741938206

Bluck, S. (2009). Special issue: Baddeley revisited: The functional approach to autobiographical memory. Applied Cognitive Psychology, 23(8), 1050-1058. https://doi.org/10.1002/acp.1609

Bolli, T., \& Hof, S. (2014). The impact of work-based education on non-cognitive skills. Journal of Research in 
Personality, 75, 46-58. https://doi.org/10.1016/j.jrp.2018.05.005

Borghans, L., Duckworth, A. L., Heckman, J. J., \& Weel, B. (2008). The economics and psychology of cognitive and non-cognitive traits. Journal of Human Resources, 43(4), 972-1059. https://doi.org/10.3368/jhr.43.4.972

Bruce, D., Phillips-Grant, K., Wilcox-O'Hearn, L. A., Robinson, J. A., \& Francis, L. (2007). Memory fragments as components of autobiographical knowledge. Applied Cognitive Psychology, 21(3), 307-324. https://doi.org/10.1002/acp.1275

Cappeliez, P., O'Rourke, N., \& Chaudhury, H. (2005). Functions of reminiscence and mental health in later life. Aging \& Mental Health, 9(4), 295-301. https://doi.org/10.1080/13607860500131427

Carneiro, P., Crawford, C., \& Goodman, A. (2007). The impact of early cognitive and non-cognitive skills on later outcomes. CEE Discussion Papers 0092, Centre for the Economics of Education, LSE.

Cherrington, S. (2018). Te Whāriki 2017: a refreshed early childhood curriculum for New Zealand. Child Research Net. Retrieved from https://www.childresearch.net/projects/ecec/2018_02.html

Cherrington, S., \& McLaughlin, T. (2018). New Zealand: Intentional Teaching and Social-Emotional Skills in New Zealand, ECEC around the World. Child Research Net. Retrieved from https://www.childresearch.net/projects/ecec/2018_03.html

Costa, P. T. Jr., \& McCrae, R. R. (2008). The Revised NEO Personality Inventory (NEO-PI-R). In G. J. Boyle, G. Matthews, \& D. H. Saklofske (Eds.), Personality measurement and testing (Vol. 2, pp. 179-198). Sage Publications, Inc. https://doi.org/10.4135/9781849200479.n9

Csikszentmihalyi, M., \& Beattie, O. V. S. (1979). Life themes: A theoretical and empirical exploration of their

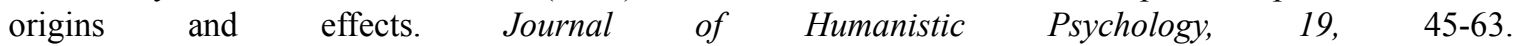
https://doi.org/10.1177/002216787901900105

Cully, J. A., LaVoie, D., \& Gfeller, J. D. (2001). Reminiscence, personality, and psychological functioning in older adults. The Gerontologist, 41(4), 89-95. https://doi.org/10.1093/geront/41.1.89

Cunha, F., \& Heckman, J. J. (2007). Identifying and estimating the distributions of ex post and ex ante returns to schooling. Labour Economics, 14(6), 870-893. https://doi.org/10.1016/j.labeco.2007.06.002

Duckworth, A. L., Peterson, C., Matthews, M. D., \& Kelly, D. R. (2007). Grit: Perseverance and passion for long-term goals. Journal of Personality and Social Psychology, 92(6), 1087-1101. https://doi.org/10.1037/0022-3514.92.6.1087

Endo, T. (2020). Aratamete-attachments-no-taisestusa-nitsuite-kangaeru [Think again about the importance of attachments]. Retrieved from https://www.note.kanekoshobo.co.jp/n/n2c2b929b5fbe

FFPQ Research Group. (2008). Kaitei-FFPQ- manual [Revised FFPQ manual (Construction of short form of Five Factor personality questionnaire)]. Kyoto: Kitaoji.

Fujishima, Y., Yamada, N., \& Tsuji, H. (2005). Construction of short form of Five Factor personality questionnaire. The Japanese Journal of Personality, 13(2), 231-241.

Goodman, A., Joshi, H., Nasim, B., \& Tyler, C. (2015). Social and emotional skills in childhood and their long-term effects on adult life: A review for the Early Intervention Foundation. Institute of Education. Retrieved from http://www.eif.org.uk/wp-content/uploads/2015/03/EIF-Strand-1-Report-FINAL1.pdf

Goto, C., \& Kasuga, K. (2017). Relationship between physical strength, motor ability and non-cognitive functional characteristics in young children: Complex relationship with Big Five. Proceedings of Japan Society of Physical Education, 68(0).

Gutman, L. M., \& Schoon, I. (2013). The impact of non-cognitive skills on outcomes for young people: Literature review, Institute of Education. Retrieved from https://helmtraining.co.uk/wp-content/uploads/2017/03/Gutman-and-Schoon-Impact-of-non-cognitive-skills -on-outcomes-for-young-people-1.pdf

Habermas, T., \& Bluck, S. (2000). Getting a life: The emergence of the life story in adolescence. Psychological Bulletin, 126(5), 748-769. https://doi.org/10.1037/0033-2909.126.5.748

Heckman, J. J. (2013). Giving kids a fair chance. Cambridge: The MIT Press, Boston Review Books.

Heckman, J. J., \& Kautz, T. (2012). Hard evidence on soft skills. Labour Economics, 19(14), 451-464. https://doi.org/10.1016/j.labeco.2012.05.014 
Higuchi, K. (2014a). Quantitative text analysis for social research-Toward the succession and development of content analysis. Kyoto, JPN: Nakanishiya Shuppan.

Higuchi, K. (2014b). KH Coder. Retrieved from https://khcoder.net/dl3.html

Ito, K., Takahashi, M., Kawahara, S., Nakajima, M., Harisaki, M., \& Kobayashi, S. (2018). "Children's play" and development of non-cognitive abilities: Evaluation and sharing of children's play by chart. Bulletin of Teacher Training Research Center, Yamagata University, 13, 69-78.

Kabaya, S. (2017). Attachment. In Endo, T (Ed.), National Institute for Educational Policy Research (pp. 59-67).

Kassenboehmer, S. C., Leung, F., \& Schuler, S. (2018). University education and non-cognitive skill development. Oxford Economic Papers, 2(70), 538-562.

Kasuga, K. (2019). Physical activity and cognitive/non-cognitive skills in young children: To mitigate various hidden issues in activity reduction. The Japanese Journal of Physical Fitness and Sports Medicine, 68(1), 36-39.

Kautz, T., Heckman, J. J., Diris, R., Weel, B., \& Borghans, L. (2014). Fostering and measuring skills: Improving cognitive and non-cognitive skills to promote lifetime success. OECD Education Working Papers 110, OECD Publishing. Retrieved from http://www.nber.org/papers/w20749

Magnus, P., Irgens, L. M., Haug, K., Nystad, S. R., Stoltenberg, C., \& The Moba Study Group. (2006). Cohort profile: The Norwegian mother and child cohort study (MoBa). International Journal of Epidemiology, 35(5), 1146-1150. https://doi.org/10.1093/ije/dyl170

Marks, G. N. (2016). The relative effects of socio-economic, demographic, non-cognitive and cognitive influences on student achievement in Australia. Learning and Individual Differences, 49, 1-10. https://doi.org/10.1016/j.lindif.2016.05.012

McLaughlin, T., Aspden, K., \& Clarke, L. (2017). How do teachers support children's social emotional competence: Strategies for teachers. Early Childhood Folio, 21, 21-27. https://doi.org/10.18296/ecf.0041

Memory. (2013). Special issue: The costs and benefits of finding meaning in the past. Memory, 21(1), 1-156. https://doi.org/10.1080/09658211.2013.771927

Minami, K., Kasuga, K., \& Goto, C. (2019). Gender differences in the relationship between physical strength/motor ability and non-cognitive functional characteristics in young children. Proceedings of Japan Society of Physical Education, 70(0).

Muto, T. (2016). How to develop non-cognitive skills to support lifelong learning, Future early childhood education (pp. 18-21). Benesse Corporation. Retrieved from https://berd.benesse.jp/up_images/magazine/018-021.pdf

Nakamura, K. (2004). Children's bodies are dangerous!. Tokyo, JPN: Nipponhyojun.

Nakano, S., Tanaka, S., Ikeda, M., \& Yamauchi, Y. (2020). Evaluation on improvement of social emotional competencies in summer camp focusing on personal characteristics: The case of UWC ISAK Japan's Summer school. Japan Journal of Educational Technology, 44(1), 23-35.

Nakano, T. (2019). Relationship between physical activity and non-cognitive skill - non-cognitive skills are strongly related to physical strength and motor ability. The Japanese Journal of Physical Fitness and Sports Medicine, 68(1), 36.

Neimeyer, G. J., \& Metzler, A. E. (1994). Personal identity and autobiographical recall. In U. Neisser, \& R. Fivush (Eds.), Emory symposia in cognition, 6. The remembering self: Construction and accuracy in the self-narrative (pp. 105-135). NY, US: Cambridge University Press.

Nelson, K. (1992). Emergence of autobiographical memory at age 4. Human Development, 35, 172-177, https://doi.org/ 10.1159/000277149

Nicole, A., \& Wang, Q. (2015). Special issue: Going global: The functions of autobiographical memory in cultural context. Memory, 23(1), 1-10. https://doi.org/ 10.1080/09658211.2014.972416

Nishida, K., Kubota, A., Tonegawa, A., \& Endo, T. (2018). The review of research on non-cognitive (socio-emotional) competence. Bulletin Paper of Graduate School of Education, 58, 31-39.

Organisation for Economic Co-operation and Development. (2005). Definition and selection of key competencies: Executive summary. OECD Publishing. Retrieved from http://www.oecd.org/pisa/35070367.pdf 
Organisation for Economic Co-operation and Development. (2015). Skills for social progress: The power of social and emotional skills. Paris: OECD Publishing.

Organisation for Economic Co-operation and Development. (2018). International early learning and child well-being study (IELS) in England: Introduction to the research. Retrieved from https://dera.ioe.ac.uk/32062/1/International_early_learning_and_child_well-being-study.pdf

Organisation for Economic Co-operation and Development. (2018). Skills for social progress: The power of social and emotional skills. Tokyo, JPN; Akashishoten.

Ota, N. (2009). Towards the future of autobiographical memory research. In K. Sato, K. Ochi, \& Y. Shimojima (Eds.), Psychology of autobiographical memory. Kyoto, JPN: Kitaohji Press.

Roberts, B. W. (2007). Contextualizing personality psychology. Journal of Personality, 75(6), 1071-1082. https://doi.org/10.1111/j.1467-6494.2007.00467.x

Roberts, B. W. (2009). Back to the future: Personality and assessment and personality development. Journal of Research in Personality, 43(2), 137-145. https://doi.org/10.1016/j.jrp.2008.12.015

Rosenthal, M. K., \& Gatt, L. (2010). Learning to live together: Training early childhood educators to promote socio-emotional competence of toddlers and pre-school children. European Early Childhood Education Research Journal, 18, 373-390. https://doi.org/10.1080/1350293X.2010.500076

Rubin, D. C., Schrauf, R. W., \& Greenberg, D, L. (2003). Brief and belief and recollection of autobiographical memories. Memory \& Cognition, 31, 887-901.

Sato, K. (2008). Function of autobiographical memory. In K. Sato, K. Ochi, \& Y. Shimojima, (Eds.), Psychology of autobiographical memory (pp. 60-75). Kyoto: Kitaohji.

Sawae, Y., Kizuka, T., \& Nakagomi, S. (2014). Physical Competence and the Future of Child Growth (pp. 3-4). Tokyo, JPN: Akashishoten.

Shonkoff, J. P., \& Phillips, D. A. (2000). From neurons to neighbourhoods: The science of early childhood development. Washington, DC: National Academy Press.

Silva, P. A. (1990). The Dunedin multidisciplinary health and development Study: A 15-year longitudinal study. Paediatric and Perinatal Epidemiology, 4(1), 76-107. https://doi.org/10.1111/j.1365-3016.1990.tb00621.x

Singer, J. A., \& Blago, P. (2004). The integrative function of narrative processing: Autobiographical memory, self-defining memories, and the life story of identity. In D. R. Beike, J. M. Lampinen, \& D. A. Behrend (Eds.), The Self and Memory (pp. 117-138). New York, NY: Psychology Press.

Singer, J. A., \& Salovey, P. (1993). Remembered self: Emotion and memory in personality. New York: The Free Press.

Suzuki, Y. (2016). What it means for children to be "fully playable". Child, Youth and Environmental Studies, 12(2), 54-62.

Suzuki, Y. (2019). Characteristics of physical expression activities among young children: How physical contact influences the body and expression. Journal of Modern Education Review, 9(2), 109-123. https://doi.org/10.15341/jmer(2155-7993)/12.07.2017/008

Suzuki, Y., \& Suzuki, H. (2017). Psychosocial effects of physical play in early childhood. Journal of Modern Education Review, 7(12), 894-905.

Taguchi, T. (2017). Non-cognitive skills and second language learning: From the perspectives of grit and self-control. Ryukoku University Center for the Promotion of Global Education Research Bulletin, 26, 63-80.

Takahashi, Y. (2016). Current trends, future perspectives, and challenges in the personality and individual differences research. The Annual Report of Educational Psychology in Japan, 55, 38-56. https://doi.org/10.5926/arepj.55.38

Takenaka, K. (2017). Kodomo-no-playfulness-wo-sodateru-Playmaker [Playmaker]. Tokyo, JPN: Sunlife.

Teddie, C., \& Tashakkori, A. (2009). Foundations of mixed methods: Integrating quantitative and qualitative approaches in the social \& behavioral sciences. Thousand Oaks, CA: Sage Publications, Inc.

The Society for FFPQ Research. (2002). Revision of FFPQ Manual (Big-Five personality questionnaire). Kyoto, JPN: Kitaohji Press. 
Tough, P. (2012). How children succeed: Grit, curiosity, and the hidden power of character. NY, New York: Houghton Mifflin Harcourt Publishing Company.

Vaughn, B. E., \& Bost, K. K. (1999). Attachment and temperament: Redundant, independent, or interacting influences on interpersonal adaptation and personality development?. In J. Cassidy, \& P. R. Shaver (Eds.), Handbook of Attachment: Theory, Research, and Clinical Applications (pp. 198-225). New York, NY: The Guilford Press.

Yamakita, M., Ando, D., Sato, M., Suzuki, K., \& Yamagata, Z. (2017). Association between play and sports in children and non-cognitive skills. Sasakawa Sports Research Grants, 339-345.

\section{Copyrights}

Copyright for this article is retained by the author(s), with first publication rights granted to the journal.

This is an open-access article distributed under the terms and conditions of the Creative Commons Attribution license (http://creativecommons.org/licenses/by/4.0/). 